\title{
Detection of terrain changes in southern Denmark using persistent scatterer interferometry
}

\author{
Stig A. Schack Pedersen, Geraint Cooksley, Marc Gaset and Peter Roll Jakobsen
}

Since 1991, a number of European satellites have acquired data of the Earth's surface for environmental monitoring. In general, a satellite will orbit the Earth in about $1 \frac{1 / 2}{2}$ hours and it takes 35 days before an ERS or ENVISAT satellite repeats radar scanning of the same position. For younger generations of satellites, such as RADARSAT and TERRA, the scanning repeat interval has decreased to 24 and 11 days, respectively, so that hundreds of radar scenes of the same place, produced over the past $c .20$ years, are now available.

Persistent scatterer interferometry (PSI) is a remote-sensing technique for measuring and monitoring land deformation that uses these radar scenes (Ferreti et al. 2001). The technique can be used to assess natural ground movements and displacement of man-made constructions.

Over the next three or more years the Geological Survey of Denmark and Greenland (GEUS) will participate in three satellite monitoring projects conducted under the auspices of the European Union. They are all funded under the Global Monitoring Environment System (GMES). The first project, which is the subject of this paper, is named TerraFirma and started in 2003 as a European Space Agency GMES service project. The second project, funded by the 7 th Framework Programme, is named SubCoast, and it will monitor subsidence in coastal areas. In Denmark, it will concentrate on the southern part of the island of Lolland. Finally a large moni-

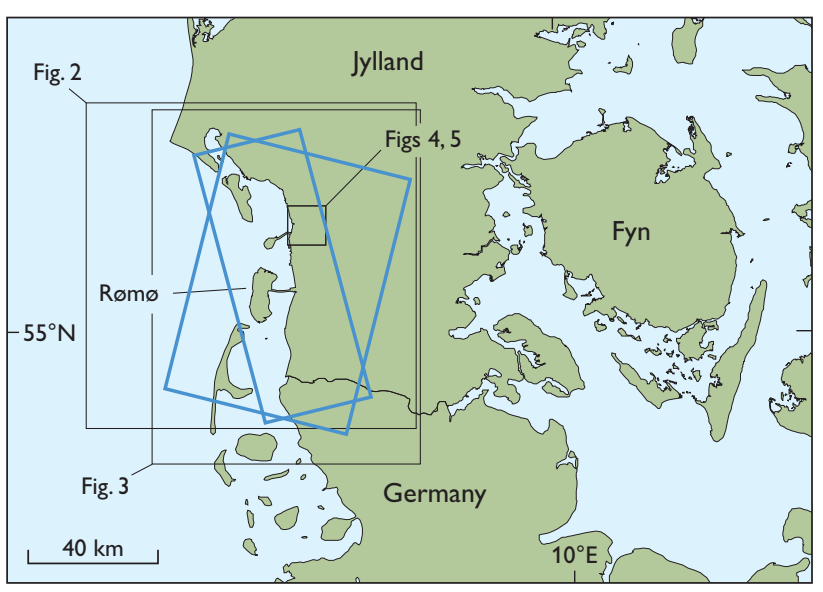

Fig. 1. Map of south-western Denmark showing the location of the investigated areas. The blue frames show areas for which data from the descending track 337 and the ascending track 403 were PSI processed. toring project named PanGeo with similar funding has begun early in 2011. Twenty-seven European geological surveys participate in PanGeo that focuses on ground movements in urban areas. Two cities in each of the participating countries are selected as targets for PSI analysis. Concerns about the effects of global climate changes are the main motivation for the GMES support to the satellite monitoring projects.

The TerraFirma project was extended with an additional three years of research and development and will continue until 2012. The project has five themes: (1) tectonic movements, (2) hydrological conditions, (3) flooding, (4) subsidence in abandoned mining areas and (5) wide-area satellite scanning. GEUS is involved in the flooding theme dealing with the increased risks of flooding of the low-lying areas in south-west Jylland, adjacent to the Danish Wadden Sea (Vadehavet). The main environmental and constructional concerns are the dykes that protect the low land areas along the coast of Vadehavet. In order to improve risk management

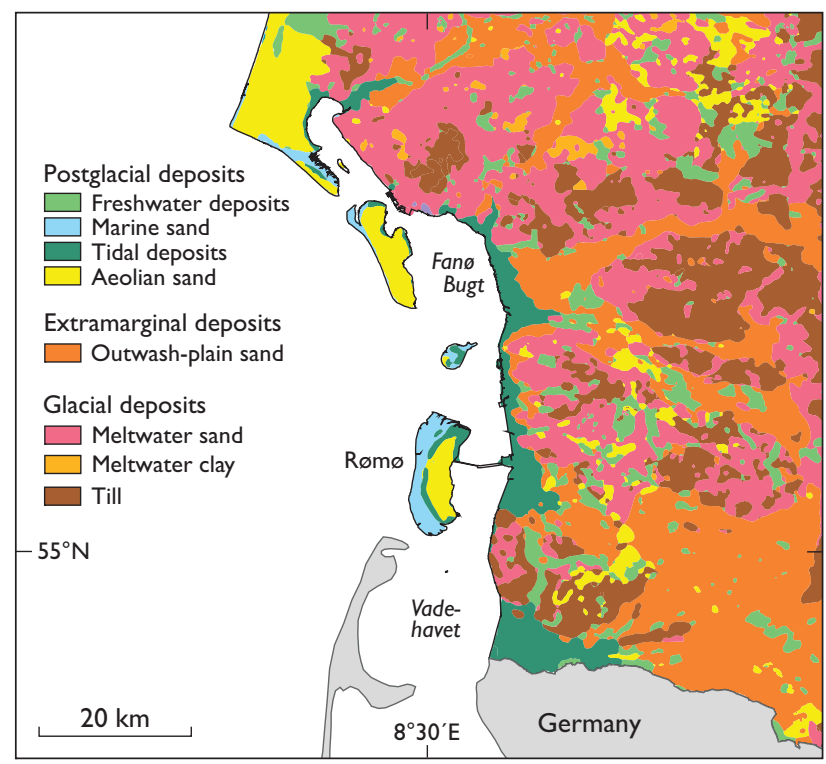

Fig. 2. Map of the surface deposits in the south-western part of Jylland. The region is dominated by glacial deposits of Saalian age. The glacial landscape is intersected by outwash plain deposits of Weichselian age. Holocene tidal deposits and recent aeolian deposits are found in the westernmost part of the map. Simplified from Pedersen (1989). 


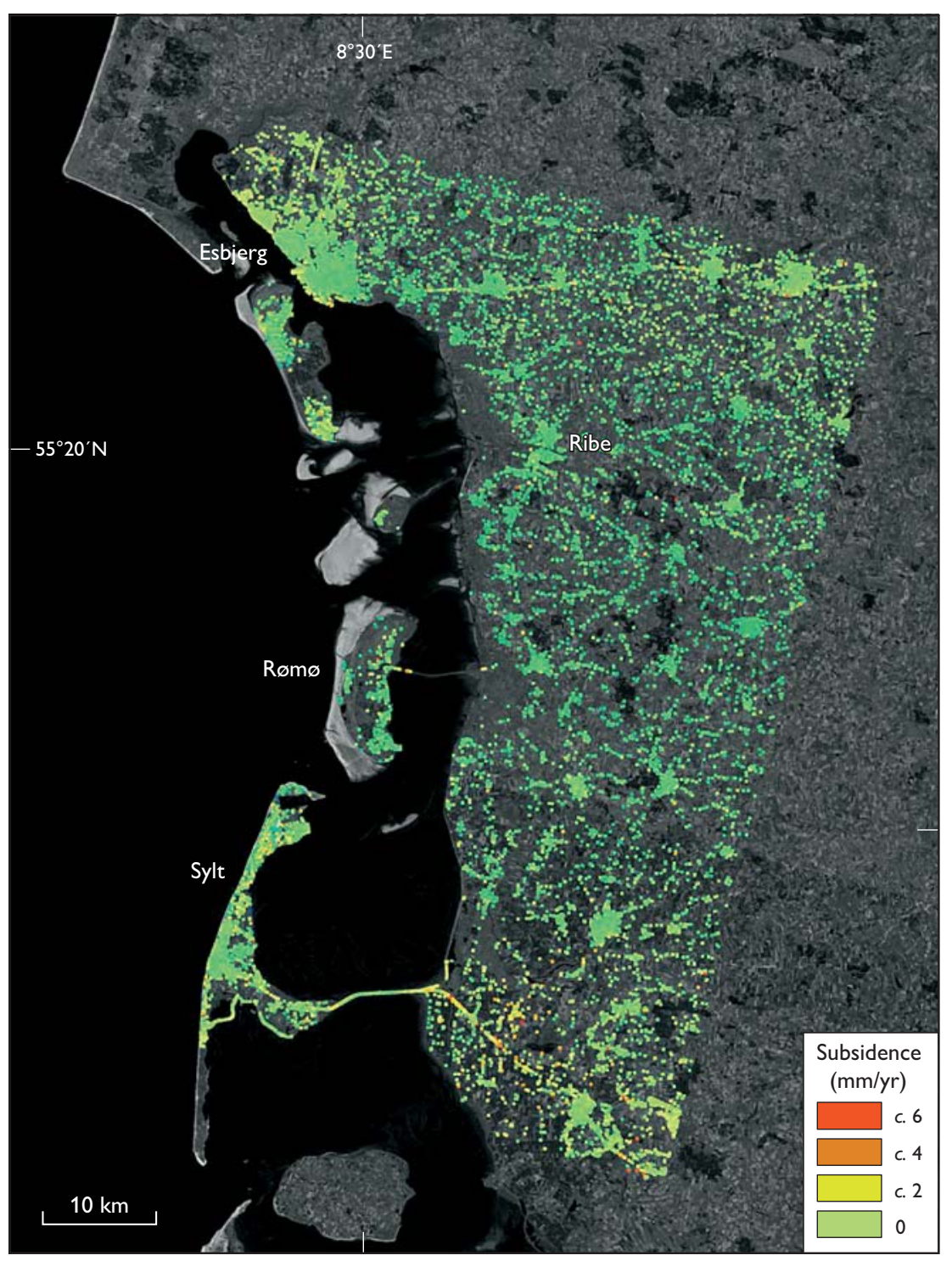

Fig. 3. Map of south-western Jylland showing PSI-processed radar data from the ERS descending track 337. Subsidence is seen along the causeway to Sylt and along the railway line east of Esbjerg. For location see Fig. 1.

moving both from north to south and from south to north.

GEUS' role in the project is to contribute with a geological and geomorphological analysis of the region (Fig. 2). Furthermore GEUS provides Geographical Information System (GIS)

and mitigation, it is also important to identify areas of land subsidence that can be caused by geological processes and by man-made impact.

\section{The Danish flood theme site}

The investigated area is located in the south-western part of Jylland, Denmark (Fig. 1) that is prone to flooding, when spring tides coincide with stormy weather. After identification of the appropriate satellite tracks for the area, GEUS provided position data for the partner Altamira Information responsible for the calibration and processing of the satellite data. The coverage by the two satellites ERS and ENVISAT and the PSI processing areas are shown in Fig. 1. The satellite line coverage consists of both descending and ascending tracks, which in broad terms means scanning by a satellite data and interpretation of the data based on a geo-scientific understanding of the region. An important GEUS contribution to the project was the conclusion of the geological map of Rømø (Jakobsen 2011). Rømø is located in the centre of the area covered by the satellite imagery.

\section{PSI data and GIS processing of satellite data}

A preliminary example of PSI-processed data is shown in Fig. 3. The orange and red pixels in the satellite image represent places where elevation changes have been detected. The PSI data have been analysed using the program ARCGIS. The first step of this is to calibrate the data to fit relevant intervals. In the second step, the point data are statistically treated to cover the geographical area by average figures in equiva- 


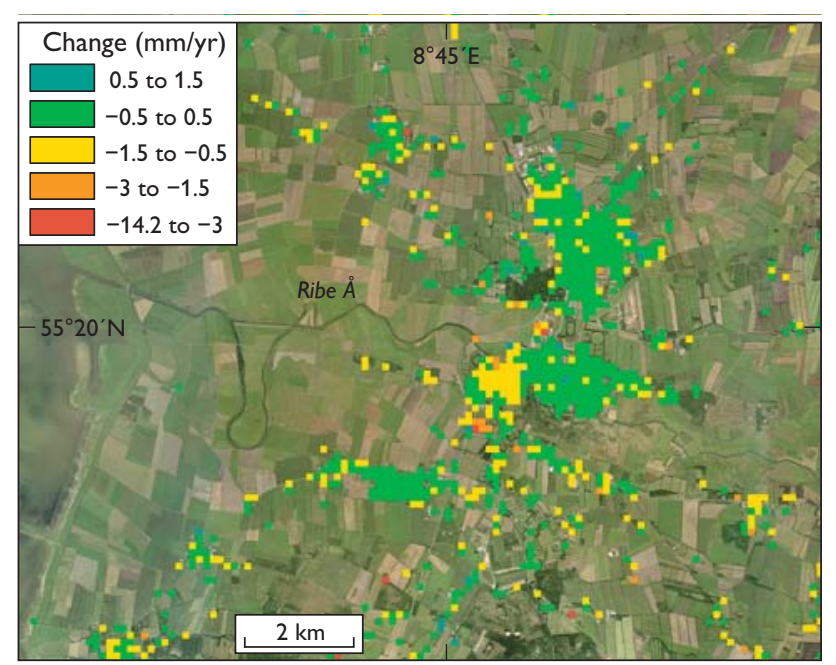

Fig. 4. Image of the area around Ribe (centre of image). The coloured pixels show places where elevation changes have been detected. The radar data have been PSI processed in a $500 \times 500 \mathrm{~m}$ grid with average values of the PSI points representing the mean values of the vertical movements (differences in vertical displacement). The concentration of yellow pixels in the western part of Ribe town is interpreted as subsidence due to urban fill. For location see Fig. 1.

lent pixels. Finally the data are compared with other terrain data, such as topographical maps, orthophotographs or terrain models based on gradient variation or geological maps.

\section{Interpretation of the persistent scatterer interferometry data}

The obvious interpretations that can be made from the preliminary persistent scatterer interferometry processing of the satellite data are terrain movements related to man-made constructions. From this it is evident that the causeway connecting the German island of Sylt to the mainland is subject to subsidence, in particular at its eastern part (Fig. 3). There is also marked subsidence along the railway line east of Esbjerg, and some of the bridges that are built across small streams are settling (Jakobsen 2008).

\section{Detailed analysis of a subsiding area: the Ribe case}

The town of Ribe and the surrounding area are described as an example of a detailed analysis using ARCGIS programming (Figs 3-5). On the map of Ribe and its surrounding, a marked subsidence is seen in the western part of the old town (yellow to red colours in Fig. 4). The subsidence rate is $-1 \pm 0.5 \mathrm{~mm} /$ year, and appears to increase to $c .-2-3 \mathrm{~mm} /$ year on the slopes close to the stream Ribe $\AA$ and a smaller

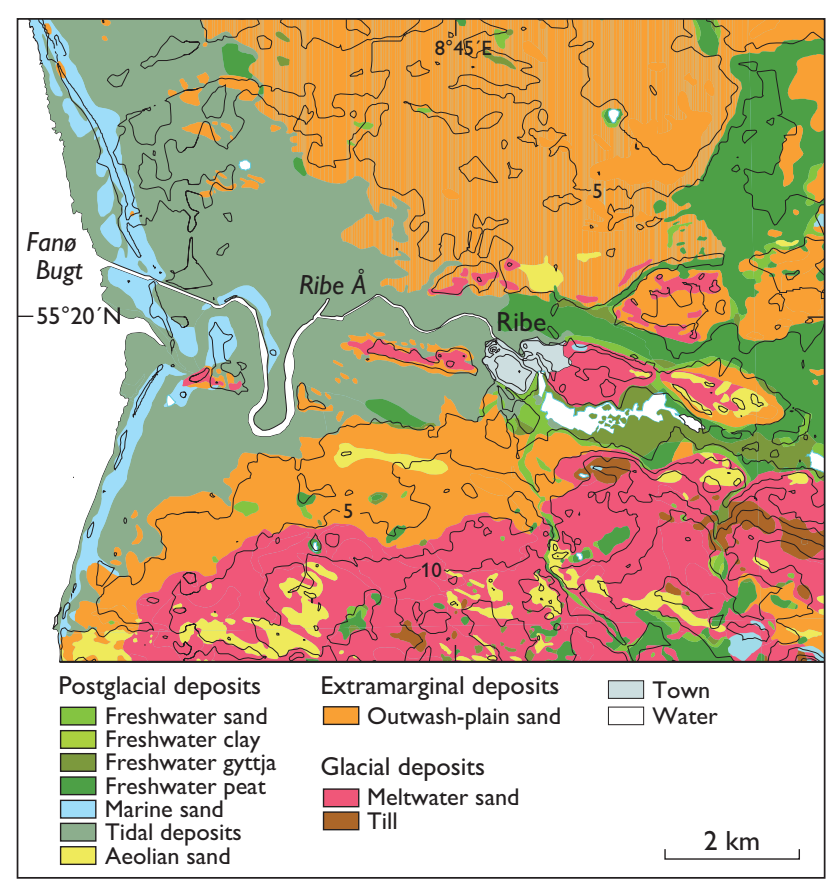

Fig. 5. Detailed geological map of Ribe and the Ribe $\AA$ area. Contour interval $2.5 \mathrm{~m}$. For location see Fig. 1.

stream south of the town (Figs 4, 5). The eastern part of Ribe appears to be comparatively stable with no significant movement recorded.

There is no obvious geological explanation for the subsidence in the western part of old Ribe. The town is located on the eastern part of an island of marine sand surrounded by meltwater sand deposited during the Saalian. During the Weichselian, the Ribe island became separated from the Saalian deposits to the north and south by eroding rivers flowing westwards from an ice margin $30 \mathrm{~km}$ to the east. Glaciofluvial sand and gravel were deposited by the rivers. In the Holocene, Ribe was situated at the boundary between an isolated sandy hill that formed an erosional remnant of the former glacial landscape surrounded by tidal flats to the west and freshwater deposits to the east. None of these geological features can explain the subsidence of western Ribe.

However, Ribe is an old town with a long and famous historical record going back to the early part of the Viking period. Around AD 1100 the town was a centre for trade with a well- developed harbour, and was favoured with privileges given by the Danish kings. During historical time, the estuary west of Ribe silted up due to accumulation of tidal deposits, and Ribe's value as a merchant town decreased. Several destructive events, including serious flooding, also affected Ribe, therefore the town has been rebuilt several times on the rubbles of former buildings. Dump and fill deposits up to $6 \mathrm{~m}$ thick lie beneath the present-day centre of old Ribe. 


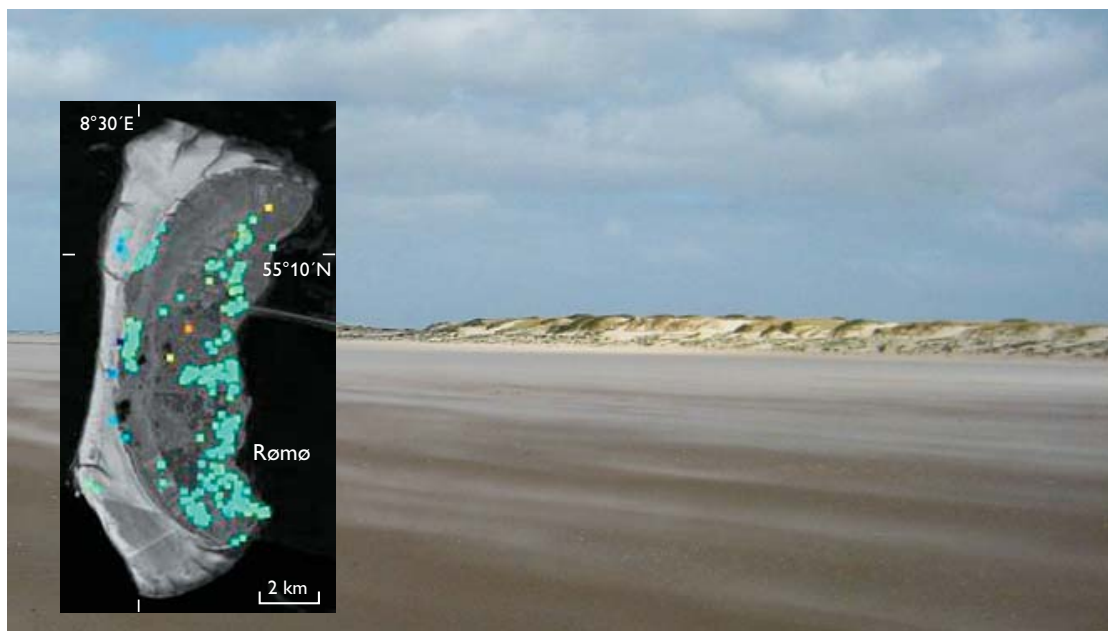

Fig. 6. Beach plain and sand dunes on the west coast of the island of Rømø. The growing dunes are identified by the persistent scatterer interferometry technique as an area with positive elevation change. Inset: Close up of the island of Rømø based on data from the ERS satellite track 401 . The scattered blue points along the west coast of the island indicate an increasing elevation of $c .2 \mathrm{~mm} /$ year, caused by sand eroded from the beach and deposited on the dunes.

Therefore we interpret the subsidence of its western part as an effect of consolidation of the historical fill below younger buildings and constructions. However, we regard the more significant displacement on the slopes towards the river north and south of the centre as an effect of additional compaction of soft organic-rich sediments found at the transition between the freshwater drainage system and the tidal environment.

\section{Detailed analysis of elevation changes: the Rømø dune field}

One of the main geological features, expected to show up in the PSI-processed data, is the concealed Tønder Graben (Lykke-Andersen 1995: Gravesen et al. 2004). However, we could not identify this structure in the data. On the contrary, it appears that the data from the ascending satellite ERS track 401 indicate a small regional uplift. The data central to this problem are being analysed further, but we note that some points along the west coast of Rømø indicate uplift (Figs 6). An uplift rate of $2 \mathrm{~mm} /$ year is indicated from the PSI data along a row of points that coincide with the outermost dunes along the flat sandy beach plain. There are no houses or constructions in this area, so we interpret the points to represent crests of recent dunes. Thus the small elevation change is caused by sand accumulation on the crest of the dunes, and the magnitude of accumulation, $2 \mathrm{~mm} /$ year, is a realistic figure for aeolian deposition in this area.

\section{Conclusions}

PSI-processed satellite data from Vadehavet (the Danish Wadden Sea) in south-west Denmark have been analysed using ARCGIS and the first results indicate that no subsurface movements can be detected. A number of constructions and urban areas are subject to minor subsidence, in the order of 2-6 mm/year. A preliminary interpretation of elevation change data from the west coast of Rømø implies that accumulation of dune sand is the reason for movements of around $2 \mathrm{~mm} /$ year. We find that PSI processing of satellite data is a powerful tool for detecting elevation changes.

\section{References}

Ferreti, A., Prati, C. \& Rocca, F., 2001: Permanent scatterers in SAR interferometry. IEE Transactions on Geoscience and Remote Sensing $39,8-20$.

Gravesen, P., Jakobsen, P.R., Binderup, M. \& Rasmussen, E.S. 2004: Geologisk set: Det sydlige Jylland, 188 pp. Copenhagen: Skov- og Naturstyrelsen.

Jakobsen, P.R. 2008: Geological evaluation of observed vertical terrain movements in the Esbjerg test area. A contribution to the ABSRATE/ Terrafirma project. Danmarks og Grønlands Geologiske Undersøgelse Rapport 2008/18, 11 pp.

Jakobsen, P.R. 2011: Geological map of Denmark, 1:50 000, 1112 III, Rømø og Mandø. Copenhagen: Geological Survey of Denmark and Greenland.

Lykke-Andersen, H. 1995: Neotektonik i Danmark. In: Nielsen, O.B. (ed.): Danmarks geologi fra Kridt til i dag, 19-30. Århus: Geologisk Institut, Aarhus Universitet.

Pedersen, S.A.S. 1989: Quaternary geological map of Denmark, 1:200 000, map sheet 3. Copenhagen: Geological Survey of Denmark. 